\title{
Structural and functional characterization of a novel gene, Hc-daf-22, from the strongylid nematode Haemonchus contortus
}

\author{
Xiaolu Guo ${ }^{1+}$, Hongli Zhang ${ }^{2+}$, Xiuping Zheng ${ }^{1}$, Qianjin Zhou ${ }^{3}$, Yi Yang ${ }^{1}$, Xueqiu Chen ${ }^{1}$ and Aifang Du ${ }^{1,4^{*}}$
}

\begin{abstract}
Background: The strongylid nematode Haemonchus contortus is a parasite of major concern for modern livestock husbandry because hostile environmental conditions may induce diapause in the early fourth-stage larvae.

Methods: A new gene Hc-daf-22 was identified which is the homologue of Ce-daf-22 and human SCPx. Genome walking and RACE were performed to obtain the whole cDNA and genomic sequence of this gene. Using qRT-PCR with all developmental stages as templates to explore the transcription level and micro-injection was applied to confirm the promoter activity of the 5'-flanking region. Overexpression, rescue and RNA interference experiments were performed in N2, daf-22 mutant (ok 693) strains of C. elegans to study the gene function of Hc-daf-22.

Results: The full length gene of Hc-daf-22 (6,939 bp) contained 16 exons separated by 15 introns, and encoded a cDNA of 1,602 bp (533 amino acids, estimated at about $59.3 \mathrm{kDa}$ ) with a peak in $L 3$ and $L 4$ in transcriptional level. The Hc-DAF-22 protein was consisted of a 3-oxoacyl-CoA thiolase domain and a SCP2 domain and evolutionarily conserved. The 1,548 bp fragment upstream of the 5'-flanking region was confirmed to have promoter activity compared with 5'-flanking region of Ce-daf-22. The rescue experiment by micro-injection of daf-22 (ok693) mutant strain showed significant increase in body size and brood size in the rescued worms with significantly reduced or completely absent fat granules confirmed by Oil red O staining, indicating that Hc-daf-22 could partially rescue the function of Ce-daf-22. Furthermore, RNAi with Hc-daf-22 could partially silence the endogenous Ce-daf-22 in N2 worms and mimic the phenotype of daf-22 (ok693) mutants.
\end{abstract}

Conclusion: The gene Hc-daf-22 was isolated and its function identified using C. elegans as a model organism. Our results indicate that $\mathrm{Hc}$-daf-22 shared similar characteristics and function with Ce-daf-22 and may play an important role in peroxisomal $\beta$-oxidation and the development in $\mathrm{H}$. contortus.

Keywords: Haemonchus contortus, Hc-daf-22, Caenorhabditis elegans, $\beta$-oxidation, Diapause

\section{Background}

The free-living nematode Caenorhabditis elegans normally develops from egg to adult through L1 to L4 larval stages in suitable environment. However, when worm density is too high or in starvation, L3 larva can transform into a dauer stage, in which worms would accumulate large amount of fat and have more spindly pharynx with thicker

\footnotetext{
* Correspondence: afdu@zju.edu.cn

${ }^{\dagger}$ Equal contributors

${ }^{1}$ College of Animal Sciences, Zhejiang Provincial Key Laboratory of Preventive

Veterinary Medicine, Zhejiang University, Hangzhou 310058, China

${ }^{4}$ Present address: Institute of Preventive Veterinary Medicine, College of

Animal Sciences, Zhejiang University, Hangzhou, Zhejiang 310058, China

Full list of author information is available at the end of the article
}

cuticle [1]. These physiological and metabolic changes can ensure a longer survival time for worms in harsh environments; normal worms can live for about two weeks while dauer worms can live for months [1]. In addition, these changes can be reversed when conditions become suitable for nematode growth, and worms can develop into regular reproductive adult stage [2]. Caenorhabditis elegans can sense population density through a group of small molecules named dauer pheromone which is secreted into environment [3]. The dauer pheromone consists of ascaroside derivatives with short, fatty-acid like side chains [3]. 
$\mathrm{Ce}$-daf-22 is homologous to the $\mathrm{N}$-terminal portion of the invertebrate sterol carrier protein $\mathrm{x}$ (SCPx) [4], and UNC-24 is homologous to the C-terminal portion of the vertebrate SCPx [5] which is one of these lip/ sterol intra cellular transport proteins [6] belonging to the well-characterized SCP2 gene family [7] and containing a sterol-binding domain (SCP2 domain). The vertebrate SCPx genes encode bipartite proteins containing 3-ketoacyl-CoA thiolase and sterol carrier protein-2 (SCP2) domains, located at the $\mathrm{N}$ - and C-terminus, respectively [8-10]. SCPx is found exclusively in peroxisomes [7]. It has been demonstrated that SCPx plays a unique role in the peroxisomal $\beta$-oxidation of branchedchain fatty acids [11] and in bile acid formation [4, 12]. In C. elegans, the daf-22 mutant was originally identified as a mutant failed to induce dauer formation and was defective in peroxisomal $\beta$-oxidation and accumulated massive amounts of very-long-chain fatty acid (VLCFAs) and very long acyl-CoAs which are toxic [5]. The massive accumulation of fatty acids and their acyl-CoAs causes severe developmental defects. Researchers found that Ce-daf-22 was also required for the biosynthesis of the short-chain fatty acid-derived side chains of the dauer pheromone [3], which indicated that there was certain link between dauer pheromone production and the general fatty acid metabolism [3]. Putative SCPx genes have been identified in parasitic nematodes Ascaris suum (ADY43045.1) and Brugia malayi [13] based on sequence similarities. However, the biological importance of SCPx in parasitic nematodes has not been yet reported.

Haemonchus contortus could also reach a special developmental stage in harsh environments such as low oxygen tension, short photoperiod, low temperature and host immune response, called diapause to avoid being expelled by hosts [2]. Little is known about details of the fatty acid $\beta$-oxidation pathway in this parasite and whether this pathway is also involved in the formation of diapause. Although significant progress in the molecular characterization of animal parasitic nematodes has been made during the last decade, the complexity of their life-cycles, the difficulties in collection of larvae of every stage, and the fact that adults cannot be cultivated in vitro, still make such studies difficult. Caenorhabditis elegans has been used as a heterologous expression system for defining the gene function of parasitic nematodes for many years. In this study, the complete cDNA of Ce-daf-22 orthologue was first identified in $H$. contortus, with the name of $H c$-daf-22. The $5^{\prime}$-flanking region of $\mathrm{Hc}$-daf-22 was examined for its promoter activity in C. elegans and the coding sequence containing the thiolase domain of Hc-daf-22 was expressed in the C. elegans daf-22 (ok693) strain by micro-injection in order to see whether it can rescue peroxisomal $\beta$-oxidation and accumulation of fat droplets in the intestine of daf-22 loss-of-function mutant or not.

\section{Methods \\ Strains}

Adults of $H$. contortus (ZJ strain) were collected from sheep abomasa (sheep abomasa were obtained from the $\mathrm{Hu}$ Zhou Slaughter house), washed by phosphate buffer saline several times and stored in liquid nitrogen for later use. The C. elegans strains were maintained on NGM agar plates seeded with E. coli (OP50 strain) at $20{ }^{\circ} \mathrm{C}$ unless otherwise stated. The strains employed here were Bristol N2 and RB859 daf-22 Y57A10C.6 (ok693) II. The daf-22 (ok693) mutant used in this study was obtained from Caenorhabditis Genetics Center (Minneapolis, MN, USA). This mutant strain has a 790 bp deletion of Ce-daf-22 gene and shows different ascaroside biosynthesis which leads to a phenotype of dauer pheromone production defect and fat associated bodies increase.

\section{Isolation of the full-length genomic CDNA of Hc-daf-22} The translated amino acids of Ce-daf-22 were used to search the European Bioinformatics Institute's parasite genomes database using tBLASTN algorithm. An EST of $H$. contortus (BF662749) with significant similarity to Ce-daf-22 was identified. Full-length cDNA was obtained from total RNA drawn from $H$. contortus adults using 5' and 3' RACE kit (Takara, Dalian, China) according to the manufacturer's instructions with gene-specific primers (Table 1). The products were cloned into pMD18-T vector and sequenced. To verify the full-length sequence of Hc-daf-22, primers were designed based on the results of $5^{\prime}$ and $3^{\prime}$ RACE to perform RT-PCR. The product was linked into pMD18-T vector and sequenced to confirm the whole sequence of this gene.

\section{Acquisition of full-length genomic DNA of Hc-daf-22}

Adult $H$. contortus worms, thawed from liquid nitrogen, were washed three times in phosphate buffer saline and homogenized in an ice bath. Total genomic DNA was extracted according to the protocol of Genomic DNA extraction kit (Takara, Dalian, China) with gene-specific primers (Table 1) designed based on the cDNA sequences and used to amplify the entire Hc-daf-22 by long-PCR from total genomic DNA of adult $H$. contortus using LA Taq. The cycling conditions were: $94{ }^{\circ} \mathrm{C}$ for $1 \mathrm{~min}$; $94{ }^{\circ} \mathrm{C}$ for $45 \mathrm{~s} ; 60{ }^{\circ} \mathrm{C}$ for $30 \mathrm{~s} ; 72{ }^{\circ} \mathrm{C}$ for $3 \mathrm{~min}$ for 30 cycles, with a final extension at $72{ }^{\circ} \mathrm{C}$ for $10 \mathrm{~min}$. The PCR products were cloned into pMD18-T vector and assembled manually after carefully sequenced. The complete cDNA sequence and genomic DNA sequence were analyzed to determine intron/exon boundaries, following the AG-GT rule. 
Table 1 Primers used in all experiments

\begin{tabular}{|c|c|}
\hline Primer ID and direction & Primer sequence $5^{\prime}-3^{\prime}$ \\
\hline Hc-daf-22 1F & TACAGACAGTGCCCGGCCATCA \\
\hline Hc-daf-22 1R & GGCAGTAATAGGGGCAGGGAACA \\
\hline Hc-daf-22 $2 \mathrm{~F}$ & GCTTCTGGCTCTTCTGGGCTCTACT \\
\hline Hc-daf-22 2R & GAAAGCGGTAACTCTGACGTTGTGCTTGC \\
\hline Hc-daf-22 F1 & ATGGGTAAATCAAAAGTATATG \\
\hline Hc-daf-22 R1 & ACTGAGTGCAGATGGTT \\
\hline Hc-daf-22 F2 & ACGCCGGCAAAGAACATAT \\
\hline Hc-daf-22 R2 & CCCTTACCGACGTCACACACAAT \\
\hline Hc-daf-22 F3 & ACTTATGAGGCTCTGGGATTG \\
\hline Hc-daf-22 R3 & GCATCGATAGTCCACTTCTITAC \\
\hline Hc-daf-22 F4 & AGGAAAATGGGTGATCAATCCGTCT \\
\hline Hc-daf-22 R4 & TCAGATTTTCGCTTTGAGCATITTC \\
\hline Hc-daf-22-SP1 & GATAGGTATGCCAGTGAACCCGAGT \\
\hline Hc-daf-22-SP2 & GCAATCGTCCAACGCCATATTCACT \\
\hline Hc-daf-22-SP3 & AATACACTCACCGGCTTCCTTCACC \\
\hline Hc-daf-22 RT F & GTATATGTGATTGGTGTCGG \\
\hline Hc-daf-22 RT R & AATATCCGACGGTAGCTT \\
\hline tub-F & TGTTCCATCACCCAAGGTATCC \\
\hline tub-R & TGACAGACACAAGGTGGTTGAGAT \\
\hline Hc-daf-22PF & AACTGCAGGATTGGTCGAGAGAGATGAAAC \\
\hline Hc-daf-22PR & CGGGATCCGATGGTCCGGGCTGCAATAAATT \\
\hline$H c-d a f-22 d F$ & TCCCCCGGGATGGGTAAATCAAAAGTATATG \\
\hline Hc-daf-22dR & GGGGTACCCAGATTTTCGCTTTGAGCAT \\
\hline $\mathrm{Ce}-\mathrm{PF}$ & GCGCTCTAGATTAATTCAATGCACAACTC \\
\hline Ce-PR & TCCCCCGGGTTTCTGGAACAATATT \\
\hline RNAi F & CCCAAGCTTGTGAACAATGCCTGCCTGCGCTT \\
\hline RNAi R & CTAGCTAGCCCTGTCGCACCGATGGG \\
\hline
\end{tabular}

Amplification of the 5'-flanking region of Hc-daf-22 gene The 5 '-flanking region of $H c$-daf-22 was amplified by using a genome walking kit (Takara) with primers designed according to the genomic sequence acquired as described above. The primary PCR was carried out using an adapter primer AP1 and specific primer Hc-daf-22-SP1 with $\sim 20 \mathrm{ng}$ of total genomic DNA from $H$. contortus adults. The cycling conditions were: $1 \mathrm{~min}$ at $94{ }^{\circ} \mathrm{C}, 1 \mathrm{~min}$ at $98{ }^{\circ} \mathrm{C}, 30 \mathrm{~s}$ at $94{ }^{\circ} \mathrm{C}, 1 \mathrm{~min}$ at $65^{\circ} \mathrm{C}, 2 \mathrm{~min}$ at $72{ }^{\circ} \mathrm{C}$ for 5 cycles; then $30 \mathrm{~s}$ at $94{ }^{\circ} \mathrm{C}, 3 \mathrm{~min}$ at $25^{\circ} \mathrm{C}, 2 \mathrm{~min}$ at $72{ }^{\circ} \mathrm{C}$, $30 \mathrm{~s}$ at $94{ }^{\circ} \mathrm{C}, 1 \mathrm{~min}$ at $65^{\circ} \mathrm{C}, 2 \mathrm{~min}$ at $72{ }^{\circ} \mathrm{C}, 30 \mathrm{~s}$ at $94^{\circ} \mathrm{C}$, $1 \mathrm{~min}$ at $44{ }^{\circ} \mathrm{C}, 2 \mathrm{~min}$ at $72{ }^{\circ} \mathrm{C}$ for 15 cycles; followed by $10 \mathrm{~min}$ at $72{ }^{\circ} \mathrm{C}$ for the final extension. Primers AP1 and Hc-daf-22-SP2 were used at the second round of PCR using $1 \mu \mathrm{l}$ first round PCR product as a template undergoing the following conditions: 15 cycles of $30 \mathrm{~s}$ at $94{ }^{\circ} \mathrm{C}$, $1 \mathrm{~min}$ at $65{ }^{\circ} \mathrm{C}, 2 \mathrm{~min}$ at $72{ }^{\circ} \mathrm{C}, 30 \mathrm{~s}$ at $94{ }^{\circ} \mathrm{C}, 1 \mathrm{~min}$ at $44{ }^{\circ} \mathrm{C}$, and $2 \mathrm{~min}$ at $72{ }^{\circ} \mathrm{C}$; followed by $10 \mathrm{~min}$ at $72{ }^{\circ} \mathrm{C}$ for the final extension. Then $1 \mu \mathrm{l}$ of the second round PCR product was used as template for the third round of PCR with primers AP1 and Hc-daf-22-SP3. The reaction conditions were the same as for the second round. PCR products of the third round were purified and cloned into pMD18-T vector for further sequencing.

\section{Sequence analysis and phylogenetic analysis}

Homology of Hc-daf-22 gene analysis was carried out using blastp at the National Center for Biotechnology Information [14]. Sequence similarities between the amino acid sequence of $H c-d a f-22$ and other related species (C. elegans, Brugia malayi and Ascaris suum) were aligned using Clustal W method. Protein motifs were identified by searching the databases of PROSITE [14] and Pfam [15]. Phylogenetic analyses were performed using neighbor-joining (NJ) and maximum likelihood (ML) methods in Molecular Evolutionary Genetic Analysis (MEGA) [16].

\section{Determination of Hc-daf-22 mRNA transcription levels in different developmental stages}

Quantitative reverse transcription PCR (qRT-PCR) with specific primers was performed using different developmental stages of $H$. contortus as templates to determine the mRNA transcriptional levels (Table 1). Briefly, the total RNA of each sample, extracted by Trizol (Invitrogen, Shanghai, China), was used to synthesize the first-strand cDNA by random priming using ReverTra Ace- $\alpha$ (Cat. No. FSK-100, TOYOBO, Shanghai, China). The qRT-PCR $(25 \mu \mathrm{l})$ using the THUNDERBIRD SYBR qPCR Mix (TOYOBO, Shanghai, China) in an ABI 7300 thermal cycler was performed under the following conditions: $50{ }^{\circ} \mathrm{C}$ for $2 \mathrm{~min}$ and $95^{\circ} \mathrm{C}$ for $1 \mathrm{~min}$ for the first cycle followed by $95{ }^{\circ} \mathrm{C}$ for $15 \mathrm{~s}, 60{ }^{\circ} \mathrm{C}$ for $15 \mathrm{~s}$ and $72{ }^{\circ} \mathrm{C}$ for $31 \mathrm{~s}$ for 40 cycles. The dissociation curve was generated under the following conditions: $95{ }^{\circ} \mathrm{C}$ for $15 \mathrm{~s}, 60{ }^{\circ} \mathrm{C}$ for $1 \mathrm{~min}, 95{ }^{\circ} \mathrm{C}$ for $15 \mathrm{~s}$ and $60{ }^{\circ} \mathrm{C}$ for $15 \mathrm{~s}$. Each sample was applied in triplicate using $\beta$-tubulin 8-9 (Accession: M76493) gene as a normaliser using specific primers (Table 1). The whole experiment was repeated three times. The mean threshold cycle (CT) values were used for further analysis.

\section{Hc-daf-22 promoter amplification and transformation of C. elegans}

The affliction of $\mathrm{Hc}$-daf-22 gene promoter was carried out using specific primers (Table 1) which were designed based on the $5^{\prime}$-flanking region of $\mathrm{Hc}$-daf-22. The PCR product was purified and cloned into the upstream of $g f p$ region of the pPD 95.77 expression vector to verify the ability of driving the green fluorescent protein (GFP) expression in C. elegans. This recombinant plasmid, 
designated as pPD 95.77Hc-daf-22-prom, was microinjected into the gonad of young adults of the wild type (N2) hermaphrodites as described together with another plasmid pRF4, which bears a dominant mutant allele of the rol-6 gene, each at a final concentration of $50 \mu \mathrm{g} / \mathrm{ml}$. The progeny worms showing the roller phenotype were collected to determine the expression patterns of GFP using a compound fluorescence microscope (Olympus IX71).

\section{Expression of Hc-daf-22 in N2 and daf-22 (ok693) strains of $C$. elegans}

The coding sequence containing the thiolase domain of Hc-daf-22 was amplified by PCR with primers listed in Table 1 with SmaI/KpnI sites underlined. The product was purified and cloned into pPD 95.77 vector between

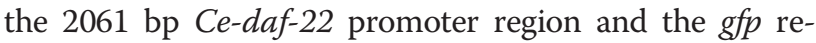
gion. The promoter region was amplified by PCR from N2 strain genomic DNA using the primers listed in Table 1 with restriction sites $X b a \mathrm{I}$ and $S m a \mathrm{I}$ underlined. The recombinant plasmid was microinjected into $\mathrm{N} 2$ and $d a f-22$ (ok693) strains as described above. Transgenic worms displaying the roller phenotype were further analyzed for examination of GFP activity as described above. CePpPD95.77-Hc-daf-22d (pPD95.77 vector with Ce-daf-22 gene promoter region and $H c-d a f-22$ gene functional domain region) was also used as a rescue plasmid, which was microinjected into daf-22 (ok693) mutants as described above. Transformants were selected based on GFP expression and rescued homozygous mutants were identified by fat staining, body size [17], growth rate [18] and brood size [19] measurements.

\section{Fat staining}

Oil red O staining was performed as described [20]. Briefly, 200-300 young adult worms were washed three times with $1 \times$ PBS and settled by gravity. Worms were resuspended with $120 \mu \mathrm{l}$ of PBS, together with an equal volume of $2 \times$ MRWB buffer containing $2 \%$ paraformaldehyde (PFA) to permeabilize the cuticle. The $2 \times$ MRWB buffer contained the following: $160 \mathrm{mM} \mathrm{KCl}, 40 \mathrm{mM} \mathrm{NaCl}, 14 \mathrm{mM}$ $\mathrm{Na}_{2}$ EGTA, $1 \mathrm{mM}$ spermidine- $\mathrm{HCl}, 0.4 \mathrm{mM}$ spermine, $30 \mathrm{mM}$ Na-PIPES $\mathrm{pH}$ 7.4, $0.2 \% \quad \beta$-mercaptoethanol. Worms were gently rocked for $1 \mathrm{~h}$ at room temperature, and allowed to settle by gravity. Worms were then washed with $1 \times$ PBS to remove PFA one time, and resuspended in $60 \%$ isopropanol for $15 \mathrm{~min}$ at room temperature to dehydrate. Isopropanol was removed after the worms had settled and worms were incubated overnight with rocking after adding $1 \mathrm{ml}$ of Oil red $\mathrm{O}$ staining solution. On the following day, the staining solution was removed and $200 \mu \mathrm{l}$ of $1 \times$ PBS $0.01 \%$ Triton X-100 added. Worms were photographed with an Olympus color camera equipped with DIC optics.

\section{Hc-daf-22d RNA interference}

Hc-daf-22d was $857 \mathrm{bp}$, from 237-1,093 bp which contained a functional thiolase domain of Hc-daf-22 gene. This fragment was amplified with specific primers (Table 1) containing the restriction sites Hind III and Nhe. The product was purified and cloned into the L4440 vector. The recombinant plasmid was transformed into HT115 (DE3) cells, an RNase III-deficient Escherichia coli strain with isopropyl- $\beta$-D-thiogalac-topyranoside-inducible T7 polymerase activity. The empty L4440 vector was also transformed into HT115 cells as control. Experiments were carried out using the standard bacterial feeding protocol [21] and repeated at least three times. Worms were observed under a microscope and any change in fat storage was confirmed by Oil red $\mathrm{O}$ staining.

\section{Statistical analyses}

Statistical analysis for $\mathrm{Hc}$-daf-22 mRNA transcription levels and parameters of $C$. elegans were carried out using one-way ANOVA in SPSS 16.0. $P$-values $<0.05$ were considered statistically significant. Graphs were made by GraghPad Prism 6 .

\section{Results}

\section{Characterization of $\mathrm{Hc}$-daf-22 gene from $\mathrm{H}$. contortus}

A 1,777 bp transcript was obtained by overlapping 3' and $5^{\prime}$ RACE results, including a 1,602 bp open reading frame (GenBank: HQ738470.1), a 58 bp 5'UTR and a 117 bp 3' UTR. The whole gene (from the ATG initiation codon to the TAA stop codon) was $6,939 \mathrm{bp}$ and consisted of 16 exons separated by 15 introns (Fig. 1). The 1,548 bp $5^{\prime}$-flanking region of $\mathrm{Hc}$-daf-22 was obtained by genome walking. Further analysis indicated that the sequence contained a TATA box, GATA-1, CCAAT binding factor, Unc-86, AP-1, AP-2, and NF $\mathrm{NB}$ sites (Fig. 2). The Hc-daf-22 ORF encoded a 533-amino-acid protein (GenBank: AEO14647.1) with a mass of $59.2 \mathrm{kDa}$ as predicted in the PROSITE database, which included the thiolases acyl-enzyme intermediate signature and thiolases signature 2 (Fig. 3a). The sequence was aligned with the DAF-22 protein of C. elegans, the sterol carrier protein of Brugia malayi, the non-specific lipid-transfer protein of Ascaris suum, sterol carrier proteins of chicken, Drosophila melanogaster, Homo sapiens and Mus musculus which showed similarities as follows: $80.3 \%, 61.9 \%, 73.0 \%$, $47.5 \%, 45.6 \%, 47.8 \%$ and $48.2 \%$, respectively (Fig. 3a). Hc-DAF-22 showed a significantly higher similarity to parasitic nematodes and the Ce-DAF-22 in amino acids (Fig. 3b). 


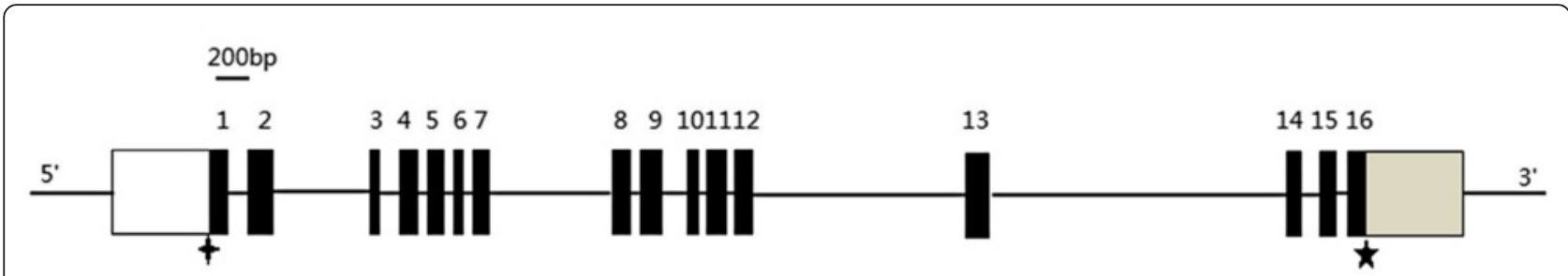

Fig. 1 Genomic structure of Hc-daf-22. The numbered boxes are exons; blank box is 5'-UTR; grey box is $3^{\prime}-U T R$. The four-point star indicates translation start codon ATG, and the five point star represents translation stop codon TAA

Transcriptional level of Hc-daf-22 throughout the lifespan of $H$. contortus

The transcription level of $H c$-daf-22 was determined at different stages throughout the lifespan of $H$. contortus by qRT-PCR. Hc-daf-22 was transcribed at detectable levels at L3, L4, adult male and female stages, with a peak in L3 and L4 stages. There was no significant difference in expression levels between male and female adults (t-test: $t=0.2052, d f=4, P=0.8474$ ) (Fig. 4).
Promoter activity analysis of the $5^{\prime}$-flanking region of $\mathrm{Hc}$ daf-22 in C. elegans

The N2 strain of $C$. elegans was transformed by microinjection with the reconstructed plasmid as described above. The Ce-daf-22 promoter was microinjected as control. Transgenic lines exhibiting the roller phenotype were selected. Fluorescence microscopy showed that GFP was mainly localized in the distal, middle and anterior part of the intestine, pharynx and excretory cells (Fig. 5) in

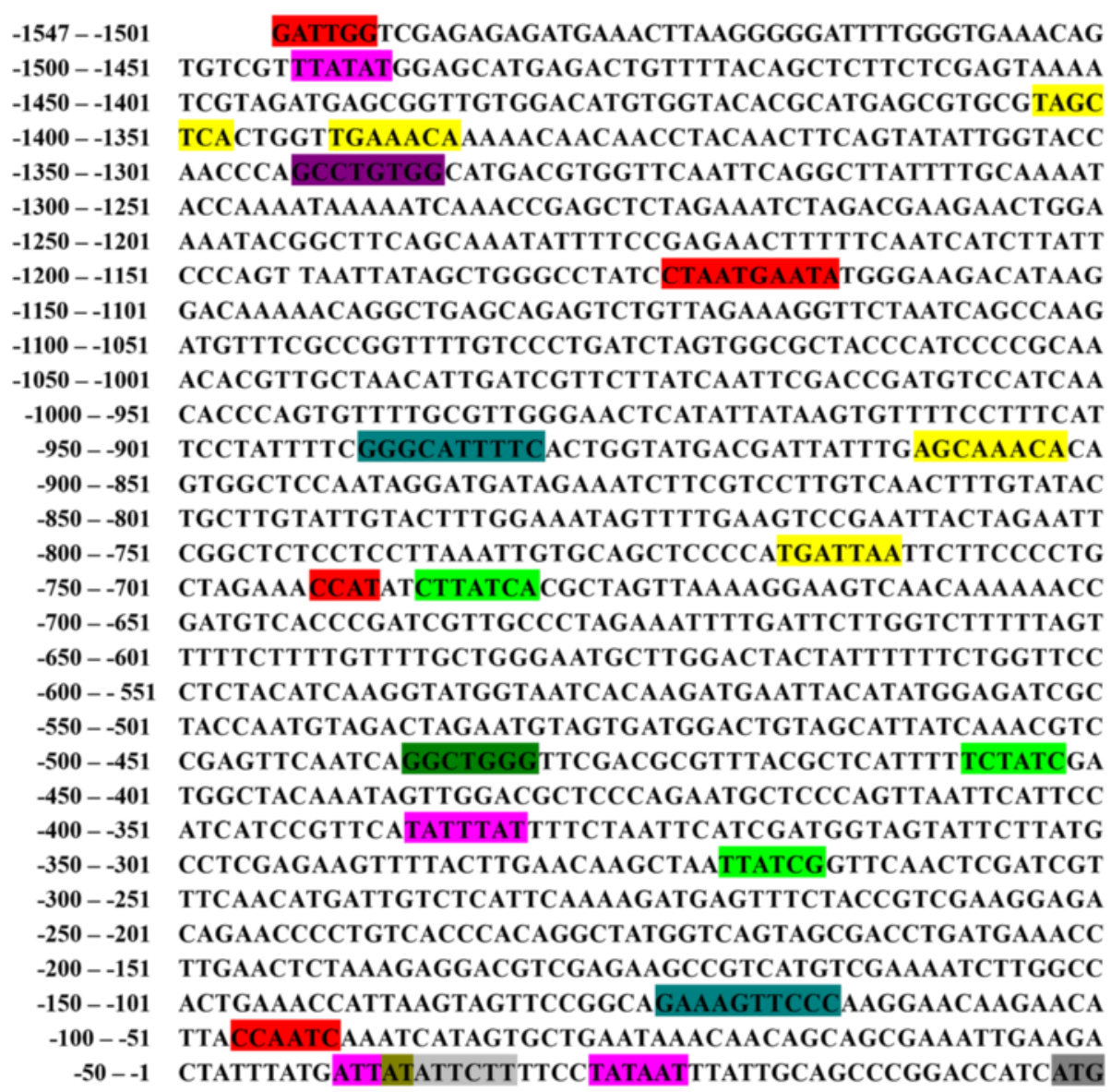

Fig. 2 Upstream domain of the Hc-daf-22 gene. The 5'-flanking region of Hc-daf-22 gene was obtained and analyzed for putative transcription factor binding sites using the Transcription Element Search System (TESS). The main predicted promoter elements are highlighted in different colors: TATA box (pink); GATA-1 binding sites (bright green); CAC-binding protein sites (green); CCAAT binding factor (red); Unc-86 (light grey); AP-1 (yellow); AP-2 (violet); NFYB (teal). The start codon ATG is highlighted in dark grey 


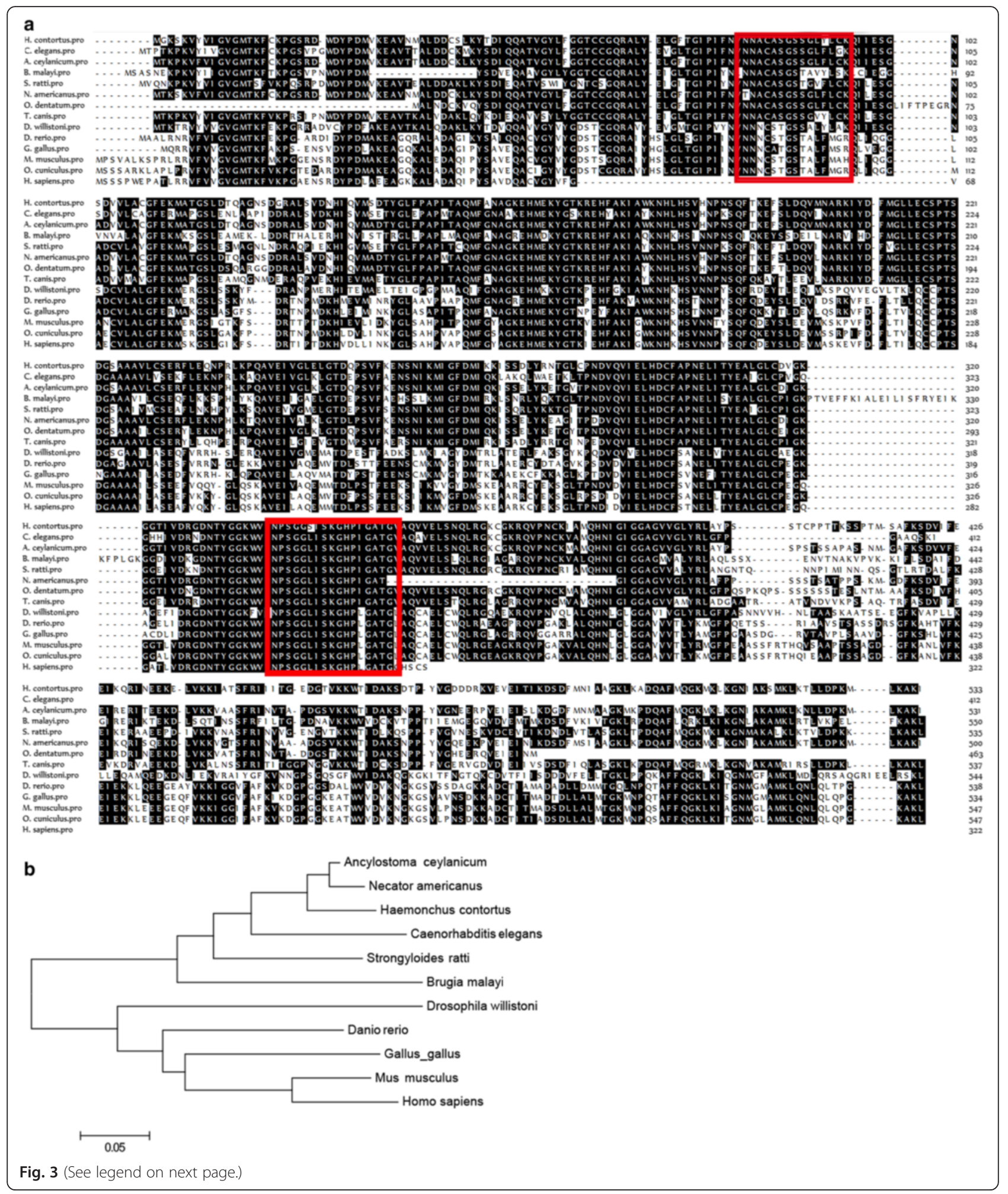


(See figure on previous page.)

Fig. 3 Characterization of Hc-daf-22 gene from H. contortus. a Alignment of the deduced amino-acid sequences of Hc-DAF-22 and other species. Protein sequences were aligned using CLUSTAL W and BoxShade. Shading in black indicates residues that are consistent. Red boxes represent thiolase acyl-enzyme intermediate signatures, the first box represents the thiolases aryl-enzyme intermediate signature and the second box represents the thiolase-2 thiolase signature. The accession numbers representing these sequences are: NP 496639.1 (C. elegans), EYC23922.1 (A. ceylanicum: Ancylostoma ceylanicum), XP 001902124.1 (B. malayi: Brugia malayi), CEF60652.1 (S. ratti: Strongyloides ratti), XP_013305621.1 (N. americanus: Necator americanus), KHJ80319.1 (O. dentatum: Oesophagostomum dentatum), KHN79232.1 (T. canis: Toxocara canis), XP_002065586.1 (D. willistoni: Drosophila willistoni), NP_957159.1 (D. rerio: Danio rerio), NP_001292129.1 (G. gallus: Gallus gallus), NP_035457.1 (M. musculus: Mus musculus), NP_001075504.1 (O. cuniculus: Oryctolagus cuniculus), NP_001007099.1 (H. sapiens: Homo sapiens). b Phylogenetic tree based on deduced amino acid sequences of Hc-DAF22 and its homologues from other species. NP 496639.1, AAB06496.1 (C. elegans), EYC23922.1 (A. ceylanicum: Ancylostoma ceylanicum), XP 001902124.1 (B. malayi: Brugia malayi), CEF60652.1 (S. ratti: Strongyloides ratti), XP_013305621.1 (N. americanus: Necator americanus), XP_002065586.1 (D. willistoni: Drosophila willistoni), NP_957159.1 (D. rerio: Danio rerio), NP_001292129.1 (G. gallus: Gallus gallus), NP_035457.1 (M. musculus: Mus musculus), NP_001007099.1 (H. sapiens: Homo sapiens)

the transgenic Hc-daf-22-promoter::gfp worms. However, compared to transgenetic Ce-daf-22-promoter::gfp worms, which could drive GFP expression in the hypodermis and throughout the intestine (Fig. 5), the level of GFP expression was clearly lower as we can see in the picture.

\section{Expression of $\mathrm{Hc}$-daf-22 in N2 strains}

In order to investigate the gene function of $\mathrm{Hc}$-daf-22 in vivo, the Hc-daf-22 coding region was overexpressed in $\mathrm{N} 2$ transgenetic line, using Ce-daf-22 5'-flanking region as promoter. As the results showed, the expression of $\mathrm{Hc}$ daf-22::gfp fusion protein could be observed in all lifecycle stages (L1, L2, L3, L4 and adult). GFP was mainly localized in the whole intestine, and more strongly, in the intestinal nuclei (Fig. 6).

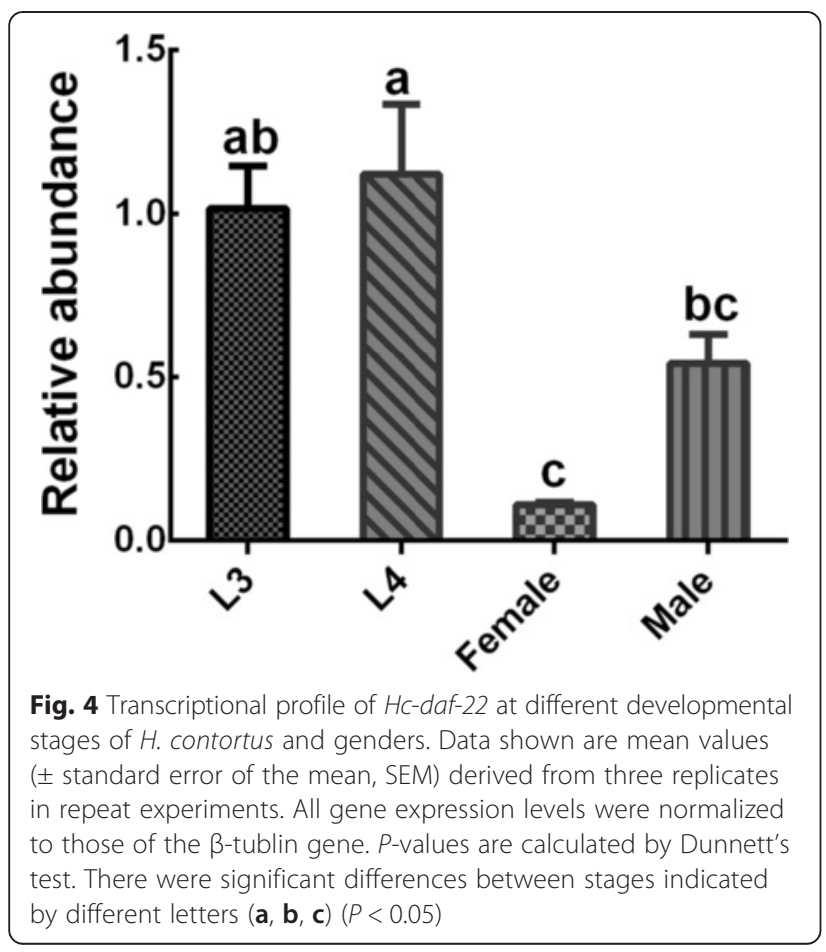

Rescue experiment of daf-22 (ok693) strain with Hc-daf-22 Based on existing data, Ce-daf-22 mutant tends to accumulate enlarged spherical intracellular structures which were confirmed to be fat droplets as a distinct phenotype and to cause defect in post-embryonic development [22]. To testify whether Hc-daf-22 could rescue the loss function of Ce-daf-22 in daf-22 (ok693) strain, daf-22 (ok693) strain was transformed with Hc-daf-22::gfp. GFP could be detected in all life stages mainly in the intestine and tail parts of the worms (Fig. 7). The rescued transformed lines of the mutant strain exhibited reduced fat storage, especially significant reduction or total disappearance of huge fat granules (Fig. 8). In addition, there was a significant increase in the body length and width of young adults of the transformed lines compared to the daf-22 (ok693) mutants (t-test: $t=10.79$, $d f=17, P<0.0001 ; t=8.857, d f=17 . P<0.0001)$. However, these measurements remained significantly lower than those of the $\mathrm{N} 2$ strain (t-test: $t=5.023, d f=17 . P<$ $0.0001 ; t=5.550, d f=17 . P<0.0001$ ) (Fig. 9c, d); the same pattern was observed for the brood size (t-test: $t=8.605$, $d f=8 . P<0.0001 ; t=3.333, d f=7 . P=0.0125$ ) (Fig. 9a). No significant difference was observed in the growth rate between daf-22 (ok693) and rescued worms (t-test: $t=$ $0.378, d f=4, P=0.7247$ ) and both were significantly lower in contrast with that of N2 strain (t-test: $t=166.3, d f=4$. $P<0.0001 ; t=144.5, d f=4 ; P<0.0001)$. Furthermore, no worms could grow into adult stage either in daf-22 (ok693) mutant or rescued worms (Fig. 9b).

\section{RNAi in C. elegans N2 strain}

RNAi experiment was carried out as described above to verify whether the Hc-daf-22 gene could silence the endogenous mRNA of Ce-daf-22 in C. elegans N2 strain. The relative quantification of mRNA levels of $\mathrm{N} 2$ and Hc-daf-22 RNAi strain showed a significant reduction in gene transcription after RNAi with Hc-daf-22 gene (t-test: $t=3.563, d f=4, P=0.0235$ ) (Fig. 10). Worms grown on $\mathrm{Hc}$-daf-22 (RNAi) plates (from egg to adult) at $20{ }^{\circ} \mathrm{C}$ were observed. There were no significant changes in body length, body width and growth rate compared with 


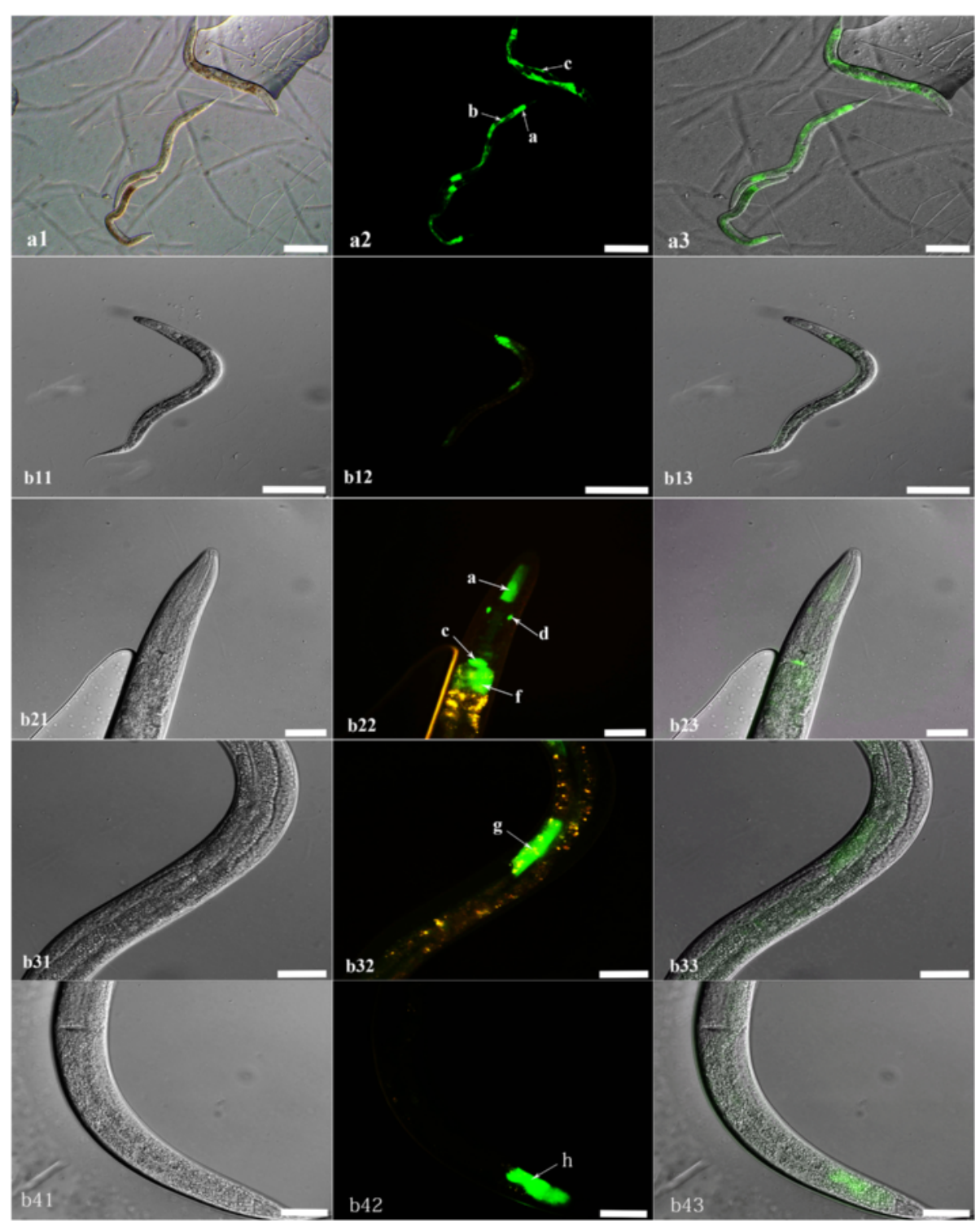

Fig. 5 Expression pattern of Ce-daf-22 and Hc-daf-22 promoter GFP fusion in C. elegans. a1-a3 Total view of Ce-daf-22 promoter-derived worms showing pharynx (arrow a), intestine (arrow b) and hypodermis (arrow c) enrichment of GFP; b11-b13 Total view of Hc-daf-22 promoter- derived worm, b21-b43 Views at higher magnification: Hc-daf-22P::GFP protein localized mainly in the pharynx (arrow a), excretory cell (arrow d) and intestine (arrows e, $f, g, h$ ). Scale-bars: $200 \mu \mathrm{m}$

N2 worms (data not shown). However, the brood size of Hc-daf-22 RNAi line was significantly decreased (t-test: $t=4.308, d f=4, P=0.0126$ ) and worms also displayed a phenotype that was richer in fat storage and accumulating more fat granules than the control worms (Fig. 11), as seen in the daf-22 (ok693) mutants.

\section{Discussion}

Recently, the whole genome of $H$. contortus was sequenced [23]; however, the precision and function annotation of the genes still need to be improved. In the present study, a new gene of $H$. contortus, $H c-d a f-22$, was isolated and characterized both in relation to gene structure and function. Hc-daf-22 is composed by 16 exons separated by 15 introns, and this composition is identical to human [24] and mouse [25] SCPx genes. Comparison of amino acid sequences of Hc-DAF-22 among different species revealed that the thiolase domain and SCP2 domain were conserved in nematodes and mammals. The C-terminal of Hc-DAF-22 contained a tripeptide (Ala-Lys-Ile), which has already been proven to be functional in porcine species [26], in contrast to the peroxisomal-targeting signal 1 (PTS1; typically Ser-Lys-Leu [27, 28] that are conserved among yeasts, plants, insects and mammals. Moreover, 


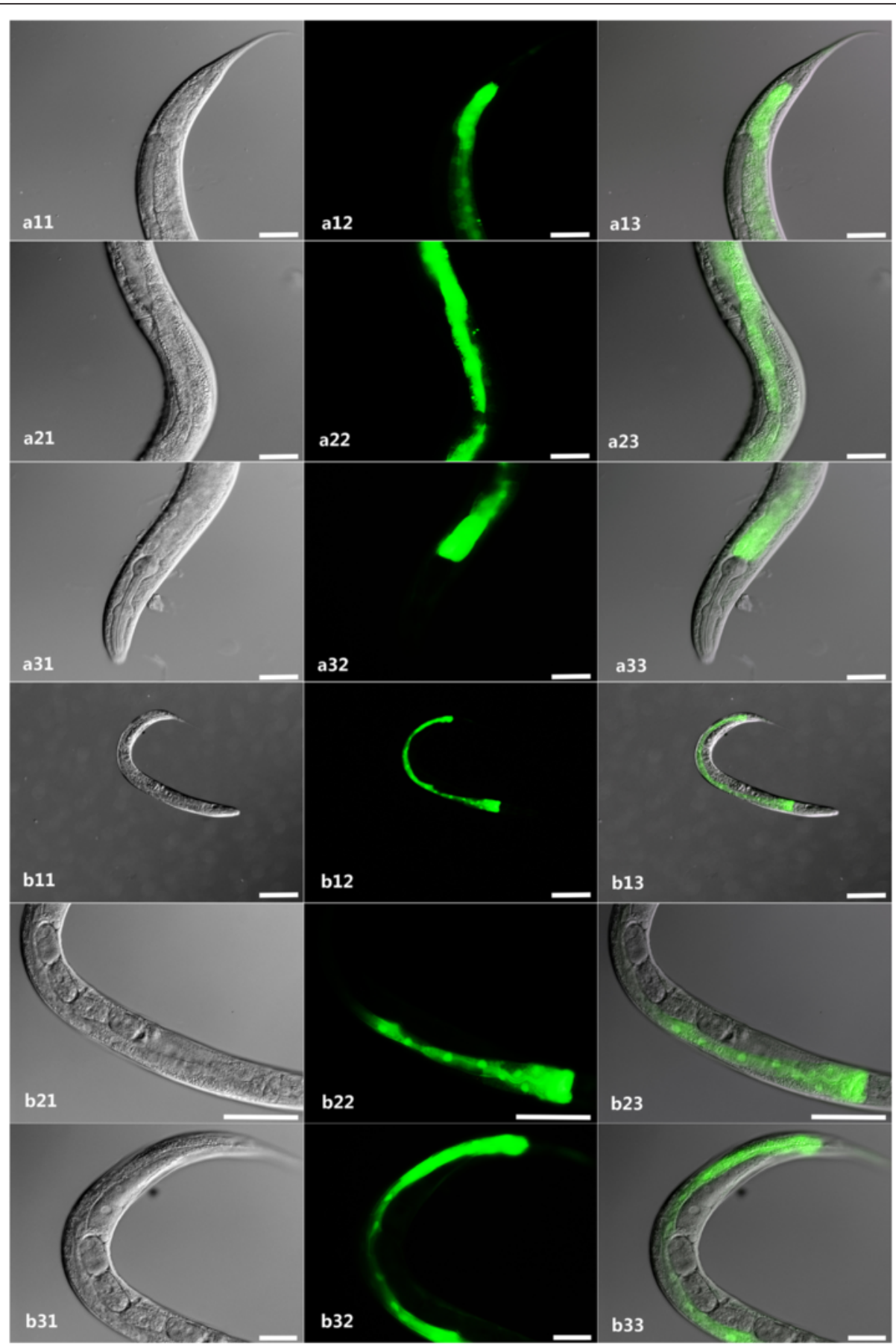

Fig. 6 Hc-DAF-22 is located in intestinal cells in C. elegans N2 worms using Ce-daf-22 promoter. The plasmid vector CeP-pPD95.77-Hc-daf-22 which contained the 2,061 bp region upstream of the Ce-daf-22 initiation codon and 1,105 bp region of the Hc-daf-22 coding sequence was constructed and injected into wild type N2 worms. The expression pattern of Hc-DAF-22 in the N2 strain is shown, GFP could be seen throughout the whole intestine in both larvae and adults with high intensity. a11-a33 L4 larvae; b11-b33 adult worms. Scale-bars: $200 \mu \mathrm{m}$

the C-terminal of Hc-DAF-22 was also found containing the amino acids that are important for SCP2 sterol transfer function (Fig. 3). The SCPx domain in the N-terminal of Hc-DAF-22 was more close to C. elegans compared to other species; however, thiolase and SCP-2 domains in $C$. elegans are coded by two separate genes and not fused together as one protein [29]. These indicate that the SCPx domain is conserved through most species, while the fusion of SCP2 domain in the Hc-daf-22 gene indicates a more advanced evolutionary position of the parasitic 


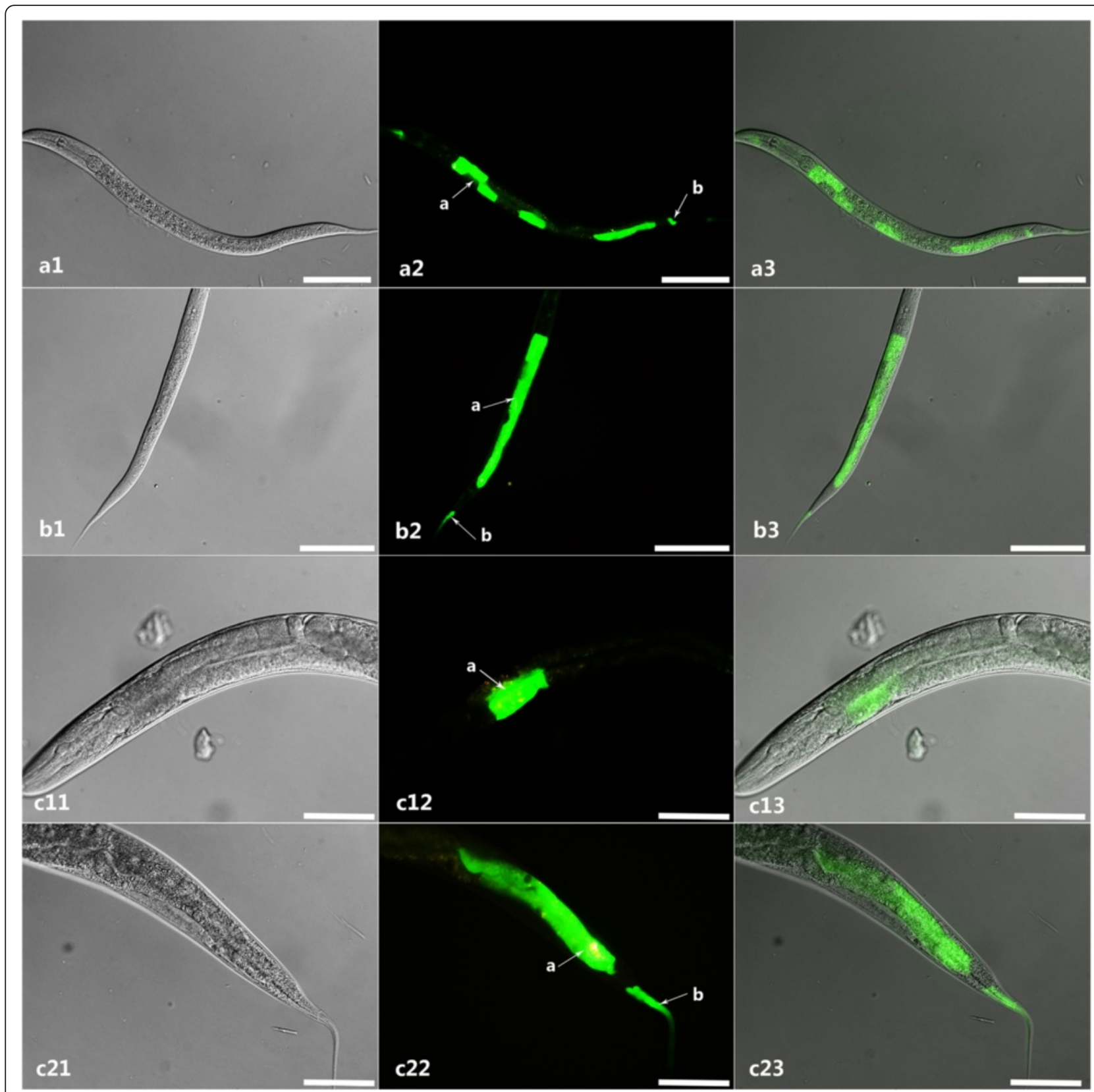

Fig. 7 Expression of Hc-daf-22 in C. elegans daf-22 (ok693). The plasmid vector CeP-pPD95.77-Hc-daf-22 was also injected into C. elegans daf-22 (ok693). The GFP was located in the intestine (arrow a) and tail (arrow b). a1-a3 L1 larvae. b1-b3 L2 larvae. c11-c23 Adult. Scale-bars: 200 um

H. contortus in relation to the free-living C. elegans. Due to the similarities in structure and function with Ce-daf-22 and other SCPx genes, Hc-daf-22 may act as a peroxisomal protein and play an important role in worm development.

We obtained the $5^{\prime}$-flanking region of $\mathrm{Hc}$-daf-22 by genome walking to analyze sequence character and verify its promoter activity with the 5 '-flanking region of Ce-daf-22 as a control. Results from our analysis showed that the 5 '-flanking region of $\mathrm{Hc}$-daf-22 contained a TATA box, GATA-1, CCAAT binding factor,
CAC-binding protein, Unc-86, AP-1, AP-2, and NFyB sites, some of which can also be found in the promoter region of the SCPx gene in humans [30]. The microinjection results indicated that this region shows promoter activity which could drive the GFP expression in the transformed lines in N2 strain mostly in the intestine area. However, compared to the control lines, the level of GFP expression was slightly low. Since the promoter region was forced to function in an alien environment of C. elegans, the driving ability could be affected and causing the relatively low GFP levels. In addition, the 


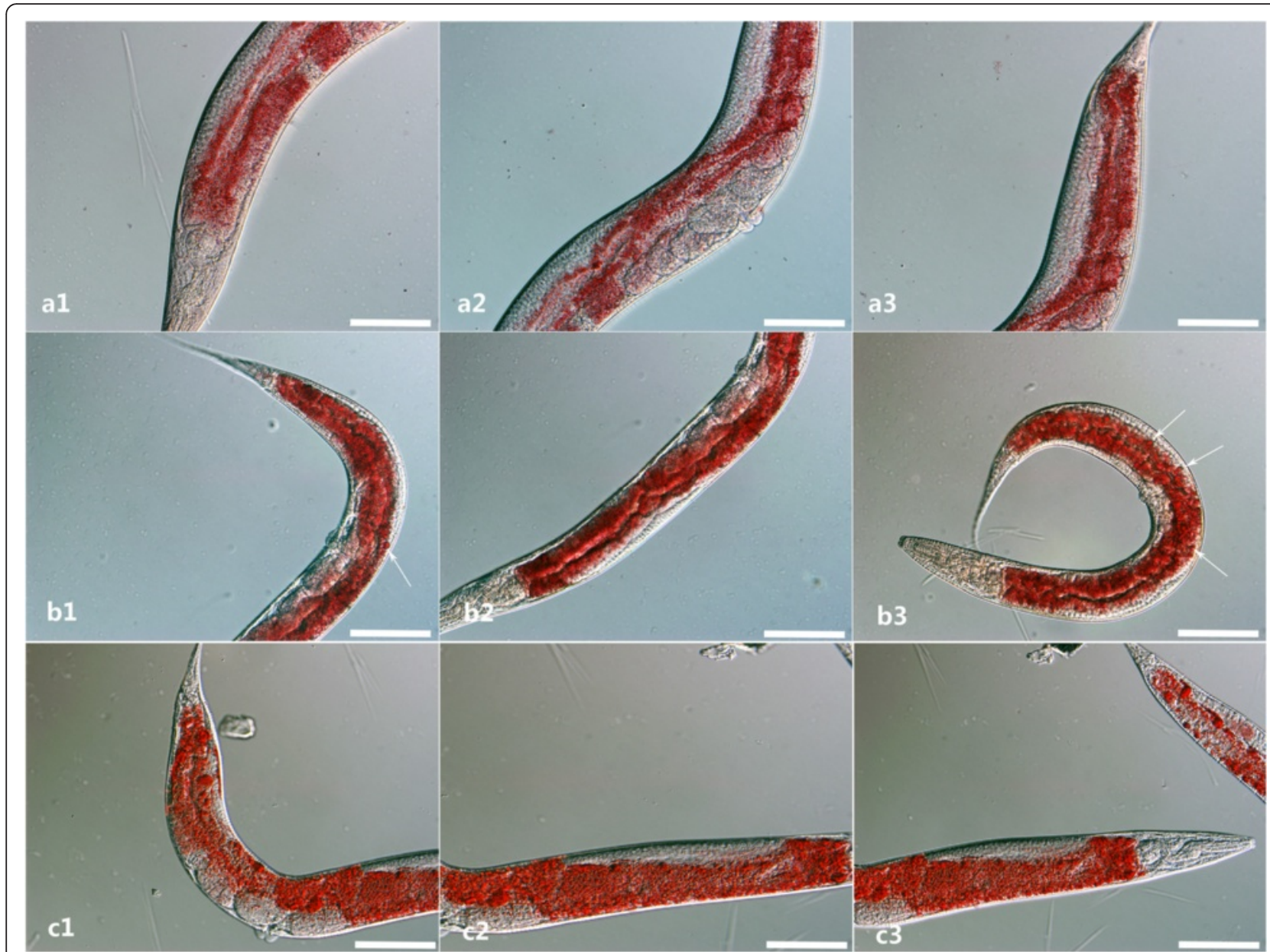

Fig. 8 Fat storage and fat granule phenotype in C. elegans N2, daf-22 (ok693), and rescued worms. a1-a3 Fat storage in N2. b1-b3 Fat storage and granules in daf-22 (ok693) strain. c1-c3 fat storage in rescued worms. Huge fat granules can be seen in the intestine of daf-22 (ok693) (arrows), while fewer or even none seen in N2 and the rescued worm. Fat staining was performed with young adults of N2, daf-22 (ok693), rescued worms using Oil red O. Scale-bars: $200 \mu \mathrm{m}$

difference of gene structure may also lead to the difference between two promoters. Hc-daf-22 contained two functional domains that are SCPx and SCP2 domains, while the Ce-daf-22 only has one SCPx domain; therefore, it was reasonable to infer that Hc-daf-22 function is more complicated than $\mathrm{Ce}$-daf-22 which may lead to a different driving pattern of the promoter. There are other possible explanations such as the first exon of Hc-daf-22 has a distinct signal which may lead to different driving pattern of the promoter just like the first exon of human SCPx gene which has influence on the promoter region [31].

To demonstrate the gene function of $\mathrm{Hc}$-daf-22 in vivo, transformations of $\mathrm{N} 2$ and daf-22 (ok693) strains with $c p-H c-$ daf-22::gfp were performed by microinjection. The detection of GFP revealed that the recombinant Hc-DAF-22 could be expressed in the intestine region in a similar pattern to $C e-d a f-22$ in $C$. elegans [18]. Besides, Hc-DAF-22 could partially restore the phenotype of the daf-22 mutant (ok693) as the fat granules were significantly reduced or even completely absent (Fig. 8). The subsequent analysis of the postembryonic development showed that Hc-DAF-22 also partially rescued the body size and brood size of the daf-22 (ok693) mutants (Fig. 9a, c, d), although no significant change was seen in growth rates. Similar results were observed by other researchers when expressing Hc-hsp-90 in C. elegans daf-21 mutant. Hc-HSP-90 could only partially rescue the phenotype of the mutant [31]. Nevertheless, other studies showed a full restore of transgenetic expression of parasitic genes in mutant strains of C. elegans. The expression of A caninum slo- 1 and C. oncophora slo-1 genes in C. elegans slo-1(js379) mutant was able to rescue the phenotype of worm locomotion and phenotypic behavior [32]. In another study, the glutamate-gated chloride channel $(\mathrm{GluCl})$ subunit of $H$. contortus was expressed in a $C$. elegans mutant (DA1316), which was able to rescue the ivermectin 

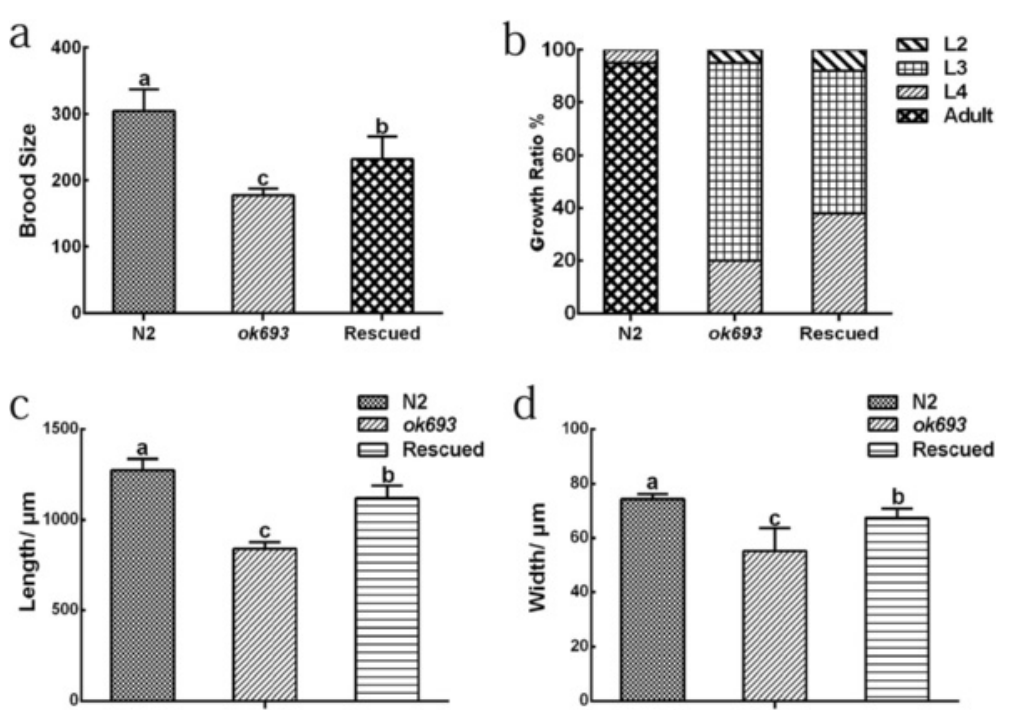

Fig. 9 Post-embryonic developmental defects of C. elegans mutant was partially rescued by Hc-daf-22. a Brood size of N2, daf-22 (ok693), rescued worms. $P$-values were calculated by Dunnett's test. Significant differences are indicated with different letters $(a, b, c)(P<0.05)$. b Developmental growth ratio of N2, daf-22 (OK693), rescued worms. Synchronized eggs were picked and the number of worms at each development stage was counted at 72 h. P-values were calculated by Dunnett's test. c Body length of N2, daf-22 (ok693), rescued worms. P-values were calculated by Dunnett's test. Significant differences are indicated with $(a, b, c)(P<0.05)$. d Body width of N2, daf-22 (ok693), rescued worms. P-values were calculated by Dunnett's test. Significant differences are indicated with $(a, b, c)(P<0.05)$

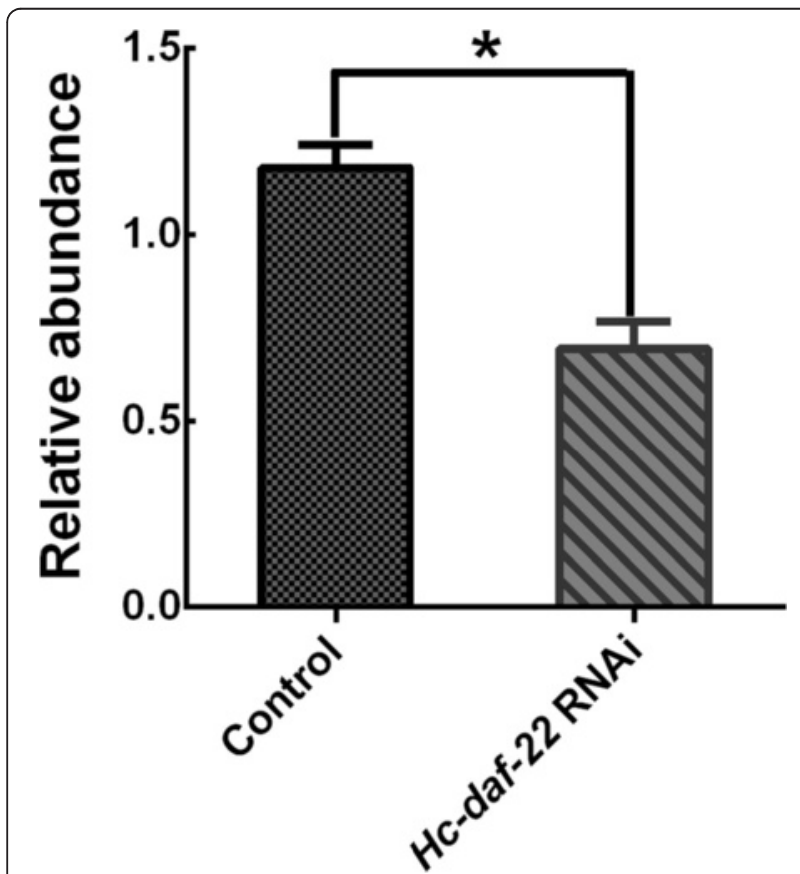

Fig. 10 Change in mRNA level of RNA interference with L4440-HC-daf22 in N2 C. elegans. The vector of L4440-HC-daf-22 was constructed and transformed into HT115 cells. Wild type C. elegans were grown on NGM plates seeded with the transformed bacteria, while the empty vector of $L 4440$ was used as a negative control. Relative quantification of Ce-daf-22 mRNA level of control N2 group and Hc-daf-22 RNAi group $(P<0.05)$ sensitivity of mutant C. elegans [33]. These data indicate that the expression of parasitic genes in mutants of C. elegans could provide a first step in understanding gene functions in vivo, some genes could fully rescue the functions of $C$. elegans mutant while some could not. The similarity of parasitic genes with the homologues in C. elegans may play a key role in the successful rate of rescue. In our case, the partial rescue of daf-22 (ok693) mutant with $\mathrm{Hc}$-daf-22 may be caused by the difference of gene structure between $\mathrm{Hc}$-daf-22 and Ce-daf-22 as described above.

RNA interference (RNAi), inducing gene silencing, has been applied successfully to $C$. elegans and provides a functional genomic platform in a range of organisms including parasitic nematodes. Although RNAi experiments in parasitic nematodes such as in Ostertagia ostertagi [34], Heligmosomoides polygyrus [35], H. contortus [36] have been successful, there is still a limited number of genes which can be successfully silenced with RNAi due to many complicated reasons, including the lack of appropriate methods of dsRNA delivery and in vitro culture systems for parasitic nematodes, differences in RNAi effector protein functionality and in the complement of RNAi effectors between nematodes [33, 35, 37, 38]. In this study, we used RNAi to silence the Ce-daf-22 of C. elegans with $H c$-daf-22 by feeding. Based on our observation, the daf-22 (RNAi) phenotype showed more fat storage and larger fat granules in a manner similar to daf-22 (ok693) mutant strain. Furthermore, the relative quantification of mRNA levels showed that $H c$-daf-22 could successfully 


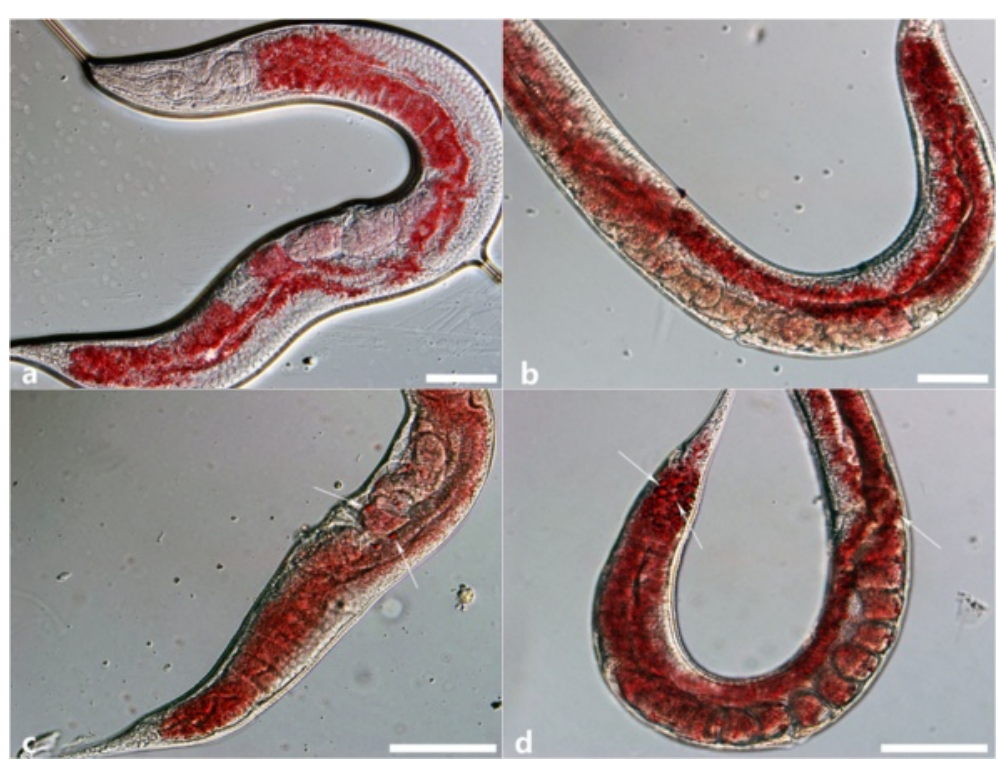

Fig. 11 RNA interference with L4440-Hc-daf-22 in N2 C. elegans by feeding. The adult worms were collected and stained with Oil red O. a Staining of N2 with no treatment. b Control adult feeding with empty L4440 stained with Oil red O. c, d Adults interfered by Hc-daf-22 stained with Oil red O; huge fat granules are indicated by arrows. Scale-bars: $200 \mu \mathrm{m}$

partially silence the Ce-daf-22, which further confirmed the similarity of gene structure and possible functions between these two genes.

Based on the expression pattern in different stages of $H$. contortus, it was noteworthy that $H c-$ daf-22 reached its peak in L3 and L4 stages. L3 stage worms have sealed mouth and live without feeding, so it is very important for them to take full advantage of the inner sources of energy like fat to survive, while L4 worms are just starting to feed on blood; this gene may play important roles in non-feeding stages of $H$. contortus.

In this study, we demonstrated that Hc-daf-22 has similar gene structure with the SCPx protein genes, which all act as peroximal $\beta$-oxidation enzymes associated in the fatty acid metabolism. We also confirmed that Hc-daf-22 could partially recued the function of Ce-daf-22 in daf-22 mutant (ok693). It is safe to infer that Hc-daf-22 may play a similar role in the same pathway in $H$. contortus. Further studies are needed to confirm its enzyme activity as thiolase, its position in the peroximal $\beta$-oxidation pathway and its relationship with diapause formation in $H$. contortus in developmental level. The results of our study primary demonstrated the possible role of this gene and showed a promising future in the research of parasitic diapause formation mechanisms.

\section{Conclusion}

In this study, a new gene $H c-d a f-22$ was identified which is the homologue of Ce-daf-22 and human SCPx. Genome walking and RACE confirmed the full length gene of $\mathrm{Hc}$ daf-22 (6,939 bp) which contained 16 exons separated by
15 introns, and encoded a cDNA of 1,602 bp. The $1,548 \mathrm{bp}$ fragment upstream of the $5^{\prime}$-flanking region was confirmed to have promoter activity compared with $5^{\prime}$ flanking region of $\mathrm{Ce}$-daf-22 by micro-injection. The rescue experiment indicated that $\mathrm{Hc}$-daf-22 could partially rescue the function of $\mathrm{Ce}$-daf-22. Furthermore, RNAi with $\mathrm{Hc}$-daf-22 could partially silence the endogenous $\mathrm{Ce}$-daf22 in N2 worms and mimic the phenotype of daf-22 (ok693) mutants. Hc-daf-22 shared similar characteristics and function with $\mathrm{Ce}$-daf-22 and may play an important role in peroxisomal $\beta$-oxidation and development in Haemonchus contortus.

\section{Abbreviations \\ Not applicable.}

\section{Acknowledgments}

We would like to thank Dr. Yang CL (Institute of Genetics and Developmental Biology, Chinese Academy of Sciences), Dr. Wang XC (the National Institute of Biological Science, Beijing) and Dr. Ren CH (Academy of Military Medical Science, Beijing) for their assistance in transgenic technique in C. elegans and for donating of vectors we needed. The C. elegans daf-22 (ok693) strain was provided by the Caenorhabditis Genetics Center, University of Minnesota.

\section{Funding}

This project was supported by grants from the National Key Basic Research Program (973 Program) of China (No. 2015CB150300), the National Natural Science Foundation of China (Nos. 31101807 and 31372426), the Natural Science Foundation of Zhejiang Province (Y201327077), and the Fundamental Research Funds for the Central Universities.

\section{Availability of data and material}

The datasets supporting the conclusions of this article are included within the article. The complete CDNA sequence of Hc-daf-22 is submitted in the GenBank database under accession number HQ738470.1 and the amino acid sequence is also submitted in the GenBank under accession number AEO14647.1. 


\section{Authors' contributions}

$X \mathrm{X}$ and $\mathrm{HZ}$ finished the isolation of Hc-daf-22, genome walking and RACE experiments, meanwhile, completed the functional rescue test of daf22(ok693) mutants, these two authors had equal contribution to this research. XZ performed the relative quantification PCR of RNAi. QZ was responsible for gene structural and phylogenetic analysis. $Y Y$ did the fat staining and promoter activity analysis. XC performed the statistical analysis of all data, AD was the corresponding author. All authors contributed to this manuscript and read and approved the submitted version.

\section{Competing interests}

The authors declare that they have no competing interests.

\section{Consent for publication}

Not applicable.

\section{Ethics approval and consent to participate} Not applicable.

\section{Author details}

${ }^{1}$ College of Animal Sciences, Zhejiang Provincial Key Laboratory of Preventive Veterinary Medicine, Zhejiang University, Hangzhou 310058, China. ${ }^{2}$ Zhejiang Center of Animal Disease Control, Hangzhou 310020, China. ${ }^{3}$ Faculty of Life Science and Biotechnology, Ningbo University, Ningbo 315211, China. ${ }^{4}$ Present address: Institute of Preventive Veterinary Medicine, College of Animal Sciences, Zhejiang University, Hangzhou, Zhejiang 310058, China.

\section{Received: 7 April 2016 Accepted: 14 July 2016}

\section{Published online: 29 July 2016}

\section{References}

1. Golden JW, Riddle DL. The Caenorhabditis elegans dauer larva: developmental effects of pheromone, food, and temperature. Dev Biol. 1984;102(2):368-78.

2. Sommerville RI, Davey KG. Diapause in parasitic nematodes: a review. Can J Zoo. 2002:80(11):1817-40.

3. Butcher RA, Ragains JR, Li W, Ruvkun G, Clardy J, Mak HY. Biosynthesis of the Caenorhabditis elegans dauer pheromone. Proc Natl Acad Sci U S A. 2009;106(6):1875-9.

4. Bun-ya M, Maebuchi M, Kamiryo T, Kurosawa T, Sato M, Tohma M, et al. Thiolase involved in bile acid formation. J Biochem-Tokyo. 1998;123(2):347-52.

5. Barnes TM, Jin Y, Horvitz HR, Ruvkun G, Hekimi S. The Caenorhabditis elegans behavioral gene unc-24 encodes a novel bipartite protein similar to both erythrocyte band 7.2 (stomatin) and nonspecific lipid transfer protein. J Neurochem. 1996;67(1):46-57.

6. Wirtz KWA. Phospholipid transfer proteins. Annu R Biochem. 1991;60(1):73-99.

7. Gallegos AM, Atshaves BP, Storey SM, Starodub O, Petrescu AD, Huang H, et al. Gene structure, intracellular localization, and functional roles of sterol carrier protein-2. Prog Lipid Res. 2001;40(6):498-563.

8. Ossendorp BC, Heusden GPH, Beer ALJ, Bos K, Schouten GL, Wirtz KWA. Identification of the CDNA clone which encodes the $58-\mathrm{kDa}$ protein containing the amino acid sequence of rat liver non-specific lipid-transfer protein (sterol-carrier protein 2). Eur J Biochem. 1991;201(1):233-9.

9. Mannaerts GP, Van Veldhoven PP, Casteels M. Peroxisomal lipid degradation via $\beta$-and a-oxidation in mammals. Cell Biochem. 2000;32(1-3):73-87.

10. Kitamura T, Kobayashi S, Okada M. Regional expression of the transcript encoding sterol carrier protein $x$-related thiolase and its regulation by homeotic genes in the midgut of Drosophila embryos. Dev Growth Differ. 1996:38(4):373-81.

11. Wanders RJA, Denis S, Wouters F, Wirtz KWA, Seedorf U. Sterol carrier protein X $(S C P x)$ is a peroxisomal branched-chain $\beta$-ketothiolase specifically reacting with 3-oxo-pristanoyl-CoA: a new, unique role for SCPx in branched-chain fatty acid metabolism in peroxisomes. Biochem Bioph Res Co. 1997;236(3):565-9.

12. Wanders RJA, Denis S, Van Berkel E, Wouters F, Wirtz KWA, Seedorf U. Identification of the newly discovered $58 \mathrm{kDa}$ peroxisomal thiolase SCPx as the main thiolase involved in both pristanic acid and trihydroxycholestanoic acid oxidation: Implications for peroxisomal $\beta$-oxidation disorders. J Inherit Metab Dis. 1998;21(3):302-5.

13. Ghedin E, Wang S, Spiro D, Caler E, Zhao Q, Crabtree J, et al. Draft genome of the filarial nematode parasite Brugia malayi. Science. 2007;317(5845):1756-60.
14. Bairoch A. The PROSITE dictionary of sites and patterns in proteins, its current status. Nucleic Acids Res. 1993;21(13):3097.

15. Bateman A, Coin L, Durbin R, Finn RD, Hollich V, Griffiths-Jones S, et al. The Pfam protein families database. Nucleic Acids Res. 2004;32 Suppl 1:D138-41.

16. Kumar S, Stecher G, Tamura K. MEGA7: Molecular Evolutionary Genetics Analysis version 7.0 for bigger datasets. Mol Biol Evol. 2016;33(7):1870-4.

17. Mörck C, Pilon M. C. elegans feeding defective mutants have shorter body lengths and increased autophagy. BMC Dev Biol. 2006;6(1):1.

18. Joo H-J, Yim Y-H, Jeong P-Y, Jin Y-X, Lee J-E, Kim H, et al. Caenorhabditis elegans utilizes dauer pheromone biosynthesis to dispose of toxic peroxisomal fatty acids for cellular homoeostasis. Biochem J. 2009;422(1):61-71.

19. Wong A, Boutis P, Hekimi S. Mutations in the $c / k-1$ gene of Caenorhabditis elegans affect developmental and behavioral timing. Genetics. 1995;139(3):1247-59.

20. O'Rourke EJ, Soukas AA, Carr CE, Ruvkun G. C. elegans major fats are stored in vesicles distinct from lysosome-related organelles. Cell Metab. 2009;10(5):430-5.

21. Timmons $L$, Court DL, Fire A. Ingestion of bacterially expressed dsRNAs can produce specific and potent genetic interference in Caenorhabditis elegans. Gene. 2001;263(1):103-12.

22. Zhang SO, Box AC, Xu N, Le Men J, Yu J, Guo F, et al. Genetic and dietary regulation of lipid droplet expansion in Caenorhabditis elegans. Proc Natl Acad Sci U S A. 2010;107(10):4640-5.

23. Erich MS, Pasi KK, Bronwyn EC, et al. The genome and developmental transcriptome of the strongylid nematode Haemonchus contortus. Genome Biol. 2013;14:R89.

24. Ohba T, Rennert H, Pfeifer SM, He Z, Yamamoto R, Holt JA, et al. The structure of the human sterol carrier protein $\mathrm{X} /$ sterol carrier protein 2 gene (SCP2). Genomics. 1994;24(2):370-4.

25. Seedorf $U$, Raabe M, Ellinghaus $P$, Kannenberg F, Fobker M, Engel T, et al. Defective peroxisomal catabolism of branched fatty acyl coenzyme A in mice lacking the sterol carrier protein-2/sterol carrier protein- $x$ gene function. Genes Dev. 1998;12(8):1189-201.

26. Möller G, Lüders J, Markus M, Husen B, Van Veldhoven PP, Adamski J. Peroxisome targeting of porcine $17 \beta$-hydroxysteroid dehydrogenase type IV/D-specific multifunctional protein 2 is mediated by its C-terminal tripeptide AKI. J Cell Biochem. 1999;73(1):70-8.

27. Gould SJ, Keller G-A, Hosken N, Wilkinson J, Subramani S. A conserved tripeptide sorts proteins to peroxisomes. J Cell Biol. 1989;108(5):1657-64.

28. Gould SJ, Keller G-A, Schneider M, Howell SH, Garrard L, Goodman JM, et al. Peroxisomal protein import is conserved between yeast, plants, insects and mammals. EMBO J. 1990;9(1):85.

29. Pfeifer SM, Sakuragi N, Ryan A, Johnson AL, Deeley RG, Billheimer JT, et al. Chicken sterol carrier protein $\mathrm{m} 2$ /sterol carrier protein $\mathrm{x}$ : CDNA cloning reveals evolutionary conservation of structure and regulated expression. Arch Biochem Biophys. 1993;304(1):287-93.

30. Ohba T, Holt JA, Billheimer JT, Strauss lii JF. Human sterol carrier protein $\mathrm{x} /$ sterol carrier protein 2 gene has two promoters. Biochemistry. 1995;34(33):10660-8.

31. Gillan V, Maitland K, McCormack G, Him NAIIN, Devaney E. Functional genomics of hsp-90 in parasitic and free-living nematodes. Int J Parasitol. 2009;39(10):1071-81.

32. Welz C, Krüger N, Schniederjans M, Miltsch SM, Krücken J, Guest M, et al. SLO-1-channels of parasitic nematodes reconstitute locomotor behaviour and emodepside sensitivity in Caenorhabditis elegans slo-1 loss of function mutants. PLoS Pathog. 2011;7(4):e1001330.

33. Glendinning SK, Buckingham SD, Sattelle DB, Wonnacott S, Wolstenholme AJ. Glutamate-gated chloride channels of Haemonchus contortus restore drug sensitivity to ivermectin resistant Caenorhabditis elegans. PLoS One. 2011;6(7):e22390.

34. Visser A, Geldhof P, De Maere V, Knox DP, Vercruysse J, Claerebout E. Efficacy and specificity of RNA interference in larval life-stages of Ostertagia ostertagi. Parasitology. 2006;133(06):777-83.

35. Lendner M, Doligalska M, Lucius R, Hartmann S. Attempts to establish RNA interference in the parasitic nematode Heligmosomoides polygyrus. Mol Biochem Parasitol. 2008;161(1):21-31.

36. Samarasinghe $B$, Knox DP, Britton C. Factors affecting susceptibility to RNA interference in Haemonchus contortus and in vivo silencing of an $\mathrm{H} 11$ aminopeptidase gene. Int J Parasitol. 2011;41(1):51-9.

37. Knox DP, Geldhof $P$, Visser A, Britton C. RNA interference in parasitic nematodes of animals: a reality check? Trends Parasitol. 2007;23(3):105-7.

38. Viney ME, Thompson FJ. Two hypotheses to explain why RNA interference does not work in animal parasitic nematodes. Int J Parasitol. 2008;38(1):43-7. 